\title{
On Attitudes to Teachers' Code-switching in EFL Classes
}

\author{
Mingfa Yao \\ School of English Language and Culture, Zhejiang International Studies University \\ 140 Wen San Avenue, Hangzhou 310012, China \\ Tel: +86-571-8157-8296 E-mail: mingfayao@163.com
}

Received: February 27, 2011 Accepted: March 26, 2010 doi:10.5430/wjel.v1n1p19

\begin{abstract}
Code-switching is commonly viewed with suspicion in EFL classes. The present article is to investigate and show the teachers and students' attitudes to code-switching (CS) used by teachers in EFL classes in China. A four-section 20-item questionnaire was developed and distributed to the students and teachers. The data from the questionnaire were tabulated, and frequencies and percentages were conducted by SPSS program. The results display that students have the similar opinions with the teachers in most of question items. This consistency suggests that teachers and students have a similar positive attitude to teachers' code-switching in EFL classroom. However there are some discrepancies in attitudes between the two samples in some question items. These discrepancies suggest that the use of code-switching in EFL classroom should be adapting to the practical teaching.
\end{abstract}

Keywords: Code-switching, Attitude, Investigation, EFL class

\section{Introduction}

In many cases, code-switching is commonly viewed with suspicion in EFL classes. Teachers and researchers in English as a second or foreign language have, on the whole, been concerned to minimize code-switching in the classroom, taking it that the switches either indicate a failure to learn the target language or an unwillingness to do so. Willis (1981), for instance, suggests that "if the students start speaking in their own language without your permission... it generally means that something is wrong with the lesson" (p. xiv). Cummins and Swain (1986) similarly argue that "progress in the second language is facilitated if only one code is used in the classroom, asserting that the teacher's exclusive use of the target code will counteract the 'pull' towards the native code" (p. 105). There also seems to be a feeling that languages should be kept strictly demarcated, despite the fact that code-switching is employed "in the repertoires of most bilingual people and in most bilingual communities” (Romaine, 1989, p. 2). In the case of monolingual native speakers, the concern is perhaps compounded by the fact that they are often unable to determine why the switching is taking place. In English teaching methodology and teacher training, it had been assumed that code-switching in the classroom was a counter-productive behavior, and the whole focus of discussion centered on ways of preventing it, with almost no consideration of what caused it in the first place.

However, there are others, mainly practitioners, who advocate careful and limited use of L1. Schmitt and McCarthy (1997) state that “a learner's L1 is one of the most important factors in learning L2 vocabulary" (p. 2). Further, it is a widespread observation that even 'ideal' bilingual speakers sometimes have to draw on vocabulary from one language while speaking another. Some supporters of L1 use in L2 teaching include Atkinson (1993), Auerbach (1993), Cole (1998), and Weschler (1997). Cole (1998) argues for selective, principled use of the L1 due to its practicality and efficiency. Cook (2001) referred to code switching in the classroom as a natural response in a bilingual situation. It is argued that language alternation in the classroom is not self-evidently counter-productive, that there is a paramount need for the subject to be researched further, and that the issue is alive with serious pedagogical implications for the practicing language teacher.

There have been some studies on the attitudes towards code-switching and its relationship with nationalism, especially with regard to language use in mostly monolingual communities. Hussein (1999) investigates Jordanian University students' attitudes toward code-switching and code-mixing to find out when and why they switch codes and the most frequent English expressions that they use in Arabic discourse. Much less attention has been systematically paid to the study of attitudes towards teachers' code-switching in language classrooms.

This study will investigate and show the in-service teachers and their students' attitudes to code-switching (CS) to find out how teachers and learners view teachers' code-switching with Chinese in EFL classroom and when and why they switch codes and the most frequent use of Chinese for what functions. 
This paper will look at this issue from two perspectives. Firstly, there is the question of the attitudes of in-service teachers to aspects of bilingual behavior, such as code-switching for some pedagogical or communicative purposes. Secondly, there is the question of the attitudes of students or learners to code-switching used in the classroom. This study addresses the following research questions:

1. What attitudes do the students and the teachers have to the teachers' code-switching in EFL classroom?

2. What does this language alternation say about these teachers' perceptions of themselves and their students?

\section{Methodology}

The participants consist of 52 English teachers and 100 students in two senior classes of those teachers. Each teacher was interviewed. These interviews elicit information about the teachers' background and training, philosophy of teaching, some simple attitudes to using Chinese in EFL classroom, and school guidelines and policies. We also ask about their views on teaching, and particularly their views regarding the role of code-switching in the EFL classroom.

The interview tries to find any matches to their actual speeches and their attitudes to code-switching in EFL classroom. A questionnaire is administered to investigate attitudes to teachers' code-switching in EFL classroom, to find out how teachers switch codes and when and why they code-switch and the most frequent use of Chinese for what functions.

The questionnaire consists of four sections and twenty items. The first five-item section elicits some information on teachers' persona according to their use of code-switching in classrooms. The rest elicit data on attitudes to functions of teachers' code-switching in subject access, classroom management and interpersonal relations respectively: Section two elicits participants' attitudes to code-switching used for subject access. Section three elicits data as to whether teachers' code-switching was used for classroom management and the last section elicits attitudes towards teachers' code-switching for interpersonal relations.

There are five choices to each question item using a Likert-type scale and choices are given marks from 5 to 1 . Teachers or students were asked to tick one of the five boxes by each statement, as appropriate.

We focused on two aspects, one is the teachers' attitudes toward teachers' CS; the other is students' attitudes toward teachers' CS. The teacher sample consists of 52 teachers from provincial key schools while the student sample is made up of 100 senior students who were in the classes of participant teachers. These students were randomly chosen from the participant classes. The Cronbach alphas are 0.852 and 0.713 respectively, which indicate that the reliability in teacher questionnaire is very high, while the reliability is acceptable in student questionnaire.

The data from the questionnaire were tabulated, and frequencies and percentages were conducted by SPSS program.

\section{Results and Discussion}

\subsection{Teachers' attitudes to classroom code-switching}

The interviews shows that, like the teachers observed by other researchers (Adendorff, 1993, 1996; Simon, 2001) many participant teachers in the research are ambivalent in their views of code-switching and reluctant or even ashamed to admit to its part in their classroom teaching practice. Although the educational climate can be characterized as prescriptive, with nationally or provincially published syllabuses and teachers' guides, most of the teachers are engaged in preparing students for the predominantly English examination for higher schools or colleges and have more active attitudes towards code switching in EFL classroom.

In this section, teachers' responses to all the questions of the questionnaire will be discussed and analyzed. Attitudes to CS in EFL classrooms will be analyzed under four subheadings: attitudes to teachers' persona in using CS (questions 1 to 5); attitudes to CS in subject access (questions 6 to 10); attitudes to CS in classroom management ( questions 11 to 15); and attitudes to CS for interpersonal relations (questions 16 to 20). The outputs from SPSS12.0 are shown in the Table 1 (see the end of the paper).

\subsubsection{Attitudes to code-switching in relation to teachers' persona}

The first question concerns the teachers' attitudes to the language proficiency of those who switch codes in EFL classroom. The table 1 shows that 80.8 percent of the teachers 'agree' or 'strongly agree' that teachers who code-switch can express themselves freely and clearly. Less than 5 percent (3.8\%) of the teachers disagree with the opinion on this question. About 15.4 percent of the teachers are not sure about this opinion on the question. This positive interrelationship is unquestionably confirmed by most of the teachers in the sample, because code-switching is accessible only to those who have had sufficient English schooling to enable them to alternate codes in their verbal behavior.

The second question is about teachers' attitudes towards whether teachers' switching will cause any difficulty in 
understanding what the teacher speaks. Contrary to the first question, the table displays that most of the participants (69.2\%) 'disagree' or 'strongly disagree' with this opinion on the question. Less than 10 percent (9.2\%) of the subject think they agree with this opinion, but more than one-fifth $(21.2 \%)$ of the teachers take no side. The result also demonstrates that in EFL classrooms, teachers' switches may cause students' misunderstanding to the teachers' utterances.

Question 3 elicits opinions from teachers varying on whether teachers' switches will pollute the languages. About 65.4\% of the teachers 'disagree' or 'strongly disagree' with the opinion on the question. However, one problem should be noted that more than 10 percent of participants agree the opinion, and 23.1 percent of the subjects are not sure of it. One of the reasons for their choice is that they do not understand what 'language pollution' is. Another reason may be that some fluent English speaking teachers tend to disagree with this language deviation, though occasionally some of them switch codes in their classes.

The fourth question concerns teachers' attitudes towards the nature of the link between switches and bilinguals' proficiency in languages. Contrary to the common view, Table1 displays that 73.1 percent of the sample contradicts the opinion on the question. It also shows that, far from being an indicator of deficiency in the use of one or both languages, there is ample evidence that code-switching or mixing requires high levels of bilingual proficiency (Poplack, 1980). That is, switches do not necessarily represent the deficiency in languages. Only three of fifty-two teachers agree with it. One of them speaks English fluently and uses more than 94 percent of target language in class.

Opinions to the fifth question vary from those of Question 4. Question 5, from the other side, asks about the same opinion on the proficiency of the teachers who code-switch. Table1 shows a different result. No more than 50 percent of the participants 'agree' or 'strongly agree' with the opinion on the question. This seems to contradict the result of question 4. Actually it does not mean that one speaker is proficient if he disagrees with opinion on the question 4. Anyway, from the results of the five questions, it is concluded that most of teachers admit the relationship between code-switching and proficiency. Generally speaking, as Ferguson (2003) pointed, "far from being an indicator of deficiency in the use of one or both languages, switching codes requires high levels of bilingual proficiency.” (p. 45)

\subsubsection{Attitudes to CS in relation to subject access}

This part tries to investigate teachers' views on whether code-switching in class will help students understand the subject matter of their lessons or not. A range of studies (Lin, 1996, Martin, 1999, Pennington, 1995, etc.) show that code-switching plays an important role in talk around written text and in commentary on, and annotation of, the meanings of these texts. The purpose clearly is to mediate textual meanings for students, who have limited control over the language of those texts. Martin (1999) provides a good example of the bilingual negotiation of the meaning of classroom texts. There are five questions on different aspects of code-switching used for text explanations.

Table1 displays an unexpected result of question 6. More than half of the teachers (51.9 percent) disagree or strongly disagree with the opinion on the question. Only 26.9 percent of the teachers agree or strongly agree with the opinion on the question and 21.2 percent of the subjects were uncertain. Some of the teachers, after interviewed, said that "we can switch to Chinese to explain some of the points in particular topics." In classes observed, the teachers switch codes according to which topic is under discussion. It might be suggested, for instance, that certain aspects of language teaching such as grammar instruction and new lexical items are preferably expressed in the mother tongue of the students.

As to the attitudes towards teachers' code-switching used in explaining the grammatical points or lexical items. Table1 shows that about three quarters (73.1\%) of the sample either 'agree' or 'strongly agree' with the opinion on the statement; whereas $15.4 \%$ 'disagree' or 'strongly disagree' with it and 11.5 percent of the teachers were not certain. This result confirms our hypothesis that, when teaching grammatical points and lexical items, teachers often choose students' native language. The result is also in accordance with that of question 6.

In the same way, it is assumed that, when encountering the cultural points in texts, teachers prefer to use L1 in order to illustrate them better. The opinions to the question 8 confirm the assumption. Most of the teachers $(76.9 \%)$ in the sample 'agree' or 'strongly agree' with the point in the question; only less than 10 percent of the teachers 'disagree' with the statement on the question and 13.5 percent of the subjects are uncertain. This is again in accordance with the idea that "we can switch to Chinese to explain some of the points in particular topics."

Responses to question 9 were similar to those offered in question 8 in that teachers sometimes use students' L1 for both eliciting answers to the teachers' question and attracting their attentions. Table1 displays that more than three quarters (76.9\%) of the teachers 'agree' or 'strongly agree' with the opinion on the question, while 11.5 percent 'disagreed' and 11.5 percent were not sure. 
When it came to question 10 about whether teachers, using code-switching, would better clarify the lesson content they taught, 67.3 percent of the sample 'agreed' or 'strongly agree' with this opinion on the question, whereas only 7.7 percent 'disagreed', but more than one-fourth of the teachers were uncertain.

Of five questions concerning code-switching in subject access, four of them are supported by most of the teachers; only the result of question 6 is beyond our expectation. It seems that code-switching is considered to be a useful strategy in teaching text contents.

\subsubsection{Attitudes to CS in relation to classroom management}

Code-switching also functions as a resource for the management of classroom discourse. Particularly, code contrast often contextualizes a change of 'frame' (Goffman1974) away from lesson content and toward some 'off-record' concern- to discipline pupils, to attend to latecomers, to gain and focus pupils' attentions. It may also demarcate talk about the lesson content from what we may refer to as the management of pupil learning; that is, negotiating task instructions, eliciting pupil responses, disciplining students, specifying a particular addressee, and so on. With regard to the following five question items in relation to classroom management, five aspects of use of code-switching are presented to the teachers.

In response to question 11 which states that "Teachers who switch codes from English to Chinese can better clarify task instruction”, the result demonstrates that responses to the opinion tilted toward agreement, 71.1 percent of the sample expressed agreement whereas only 13.5 percent disagreed, and 15.4 of the teachers take no extreme sides. It is believed that code-switching can help teachers better clarify classroom task instruction.

With the opinions to the statement of "teachers who switch codes from English to Chinese can better discipline the students", teachers also tended to agree with the statement. The result displays that 55.8 percent of the sample expressed agreement, whereas 32.6 percent expressed disagreement and 11.5 percent were uncertain. Some teachers are well aware that using code-switching to discipline a pupil is not the best way. However, one of the teachers, who speak English fluently, switches to Chinese to blame and discipline some students when they had a dictation.

To question 13, which states that "teachers who code-switch from English to Chinese can better engage students' attention”, 53.9 percent 'agree' or 'strongly agree', while 22.1 percent 'disagree' and 'strongly disagree' and one-fourth of the teachers were not certain. Again code-switching is perhaps not the best way for engaging students' attention in classroom teaching. Some of the teachers, however, reported that they often used Chinese to engage students' attention when some of students are absent-minded.

Responses to the statement of "teachers who switch codes from English to Chinese can better request quiet", indicate that only half of the teachers (50\%) 'agreed', whereas 26.9 percent 'disagreed' and 23.1 percent of the teacher were uncertain. It seems that code-switching for requesting the students' to be quiet is not agreed by many of the teachers. However, one participant teacher said that he often used Chinese to ask students to be quiet.

To the statement of "teachers who switch codes from English to Chinese can better direct (call on) students', 67.3 percent of the sample 'agreed' or 'strongly agreed' with it, whereas only 13.5 percent 'disagreed' with it and 19.2 percent who were uncertain. This is in line with Arthur (1996) who has argued that code-switching may be used for addressee specification.

All above five questions about using code-switching in classroom management do not gain high percentage of agreement or disagreement. From interviews to the participant teachers, they usually do not need to discipline the students when teaching or doing exercises, especially in senior two grades.

\subsubsection{Attitudes to CS in relation to interpersonal relations}

Although it is clear that the following questions to attitudes overlap with the previous section, this category of attitudes to CS for interpersonal relations highlights the fact that the classroom is not only a place of formal learning but also a social and affective environment in its own right, one where teachers and learners negotiate relationships and identities. In EFL classrooms in other studies (Adendorff, 1993; Canagarajah, 1995; Lin, 1996), English indexes a more distanced, formal (or institutional) teacher-student relationship and the local native language - Zulu, Tamil, or Cantonese, for example-indexes a more personal one. To build rapport with individual students, create greater personal warmth and encourage greater learner involvement, a teacher may, therefore, when the occasion is appropriate, switch to the students' native language. How about teachers' attitudes to CS in relation to interpersonal relation in our sample? The following questions pursue this question from different aspects.

With the statement of "Teachers who switch codes from English to Chinese can better encourage students", the result shows that half of the teachers tended to 'agree' or 'strongly agree', whereas, only 26.9 percent of the sample expressed disagreement and 23.1 percent were uncertain, so the majority approve of this statement. This ties in well with the fact 
that in secondary EFL classroom teachers are aware that it is necessary to encourage students when appropriate.

The opinions to question 17 are similar with those of Question 16, about 48.1 percent of the teachers showed agreement, 28.8 percent showed disagreement and 23.1 percent were uncertain. These two questions investigate the same thing about how to stimulate students' interests in English learning.

To the following three question items, there are different opinions. In responding to question 18, only 9.6 percent of the sample showed 'disagreement' to the statement and higher percentage of the sample (69.3\%) agreed with the statement. 21.2 percent of teachers were uncertain to the statement. Most participant teachers reported that they would switch to Chinese to tell a joke or short story to enliven the atmosphere of their classes. Responses to question 19 show that 46.2 percent 'agreed' or 'strongly agreed' compared to 30.7 percent who 'disagreed' or 'strongly disagreed' and 23.1 percent who were unsure. It contradicts our expectation that a higher percentage would consent to the opinion of the statement. To the last question item, whereas 65.4 percent of the sample 'agreed' or 'strongly agreed', 19.2 'disagreed or strongly disagreed and $15.4 \%$ expressed uncertainty. In parallel with its role in the management of the affective climate (encouragement and praise), CS is also a resource for better negotiating with students or learner.

\subsection{Students' attitudes to code-switching}

\subsubsection{Attitudes to CS in relation to teachers' persona}

Table1summarizes the whole student sample (100 students) attitudes to teachers' code-switching in EFL classroom. All the numbers are counted as percentages. Compared to the teachers' attitudes to Question 1, whereas a higher percentage (93\%) of the students 'agrees' or 'strongly agrees' with the opinion on the question, only 2 percent of the student sample 'disagree' with it. To other four questions in this section, students gain $65 \%, 64 \%, 80 \%$ and $19 \%$ respectively in disagreement and 'strong' disagreement', compared to teachers' $69.2 \%, 65.4 \%, 73.1 \%$ and $21.1 \%$. It seems that there is no difference between the two samples in these question items. This will be tested in the following section.

\subsubsection{Attitudes to CS in relation to subject access}

With regard to questions 6 to question 10 eliciting attitudes to teachers' code-switching in relation to subject access, it was evident that responses to Question 6 tilted toward agreement: 48 percent of the sample expressed agreement or 'strong' agreement whereas 25 percent expressed disagreement and 27 percent expressed uncertainty. The result shows the other extreme in comparison to teachers' responses (51.9\% expressed disagreement or 'strong' disagreement, whereas 26.9 percent expressed agreement or strong agreement).

Responses to question 7 indicate that a very high percentage (93\%) of student sample either 'strongly agrees' or 'agrees' compared to 73.1 percent of the teachers who 'agree' or 'strongly agree'. In responding to the rest three questions, $86 \%$, $81 \%, 88 \%$ of the student sample expressed agreement or 'strong' agreement with each statement, whereas lower percentages $(76.9 \%, 76.9 \%, 67.3 \%$ respectively) of the teacher sample expressed the same opinion. It is believed that students expect more Chinese when teachers explain the cultural topics, grammatical and lexical items, and something concerned with the lesson content.

\subsubsection{Attitudes to CS in relation to classroom management}

Questions eliciting students' attitudes to teachers' switches in relation to classroom management are question 11 to question 15. Reponses to question 11 indicate that $69 \%$ either 'agree' or 'strongly agree', whereas only 8\% disagree, compared to $71.1 \%$ of the teachers who expressed agreement. It is obvious that both teachers and students mostly expect the teacher to clarify what he wants students to do. To the Question 12, 46\% 'disagreed' or 'strongly disagreed', only 31\% 'agreed' or 'strongly agreed', in comparison to $55.8 \%$ of the teachers who 'agreed' or 'strongly agreed' and $32.6 \%$ 'disagreed' with the statement. The two samples go to the opposite extremes in attitudes to this statement. In response to question $13,41 \%$ of the students 'agreed' or 'strongly agreed' compared to $27 \%$ who 'disagreed' or 'strongly disagreed'. In comparison to the teacher sample, a relatively high percentage of the teachers (53.9\%) showed agreement or 'strong' agreement. It seems that teachers more likely tend to use students' first languages to engage students' attention (Merritt et al 1992). To the statement of Question 14, 25\% 'agreed', 43\% 'disagreed' or 'strongly disagree' and about one-third showed uncertainty. Compared to the teacher sample, much higher of the percentage $(50 \%)$ of the teachers showed agreement or strong agreement. One of the teachers shifted codes from English to Chinese to request silence after having a dictation, because it was noisy and some students wanted to peep and copy others' answer. Response to the last question 15 , indicate that $66 \%$ 'agreed' or 'strongly agreed', compared to $12 \%$ who 'disagreed' or 'strongly disagreed' and $22 \%$ who were uncertain, while in teacher sample responses showed almost the same agreement (67.3\%).

\subsubsection{Attitudes to CS in relation to interpersonal relations}

The last five questions elicit attitudes to teachers' code-switching in relation to interpersonal relations. Responses to 
question 16, show that 40 percent of the students 'agreed' or 'strongly agreed', compared to 50 percent of the teachers 'who agreed' or 'strongly agreed', whereas the percentages of the disagreement or strong disagreement in two sample are almost equal ( $26 \%$ to $26.9 \%$ ). This result demonstrates that most of the students are not often encouraged by our teachers and need much more encouragement from their teachers. This is proved by our survey and observation. In responses to question 17, 39 percent showed either 'disagreed' or 'strongly disagreed', and only 32 percent 'agreed' with the statement in comparison to 48.1 percent of the teacher sample who 'agreed'. The reason for that is also due to the fact that most of the teachers in EFL classes rarely use praising words. This is also proved in our class observation. No more than 5 percent of the units are used in most of the classes. Responses to question 18 indicate that 69.3percent 'agreed' or 'strongly agreed' compared to 9.6 percent who 'disagreed' and 21.2 percent who are not sure, while almost the same percentages $(71 \%, 9 \%$, and $20 \%$ respectively) are showed in the teacher sample. It is expected that teachers would take various kind of methods to enliven their class, including shifting codes to speak a joke. In fact, from the data collected and our observation, I find very few instances of jokes or humor in classes. In responses to Question 19, 46.2 percent 'agreed' or 'strongly agreed', more that 30 percent of the students disagreed and 23.1 percent take no extremes. In comparison to the teacher sample, a higher percentage (53\%) of the subjects showed agreement. To the last question, "teachers who switch codes from English to Chinese can better negotiate with students (reduce distance)", responses show that 65.4 percent 'agreed' or 'strongly agreed' in comparison to 19.2 percent who 'disagreed', while in teacher sample almost the equal percentage (66\%) of the subjects showed agreement or 'strong' agreement.

\subsection{Comparisons of attitudes to teachers' CS between teachers and students}

Because teachers and students are two groups from different unrelated samples, T-test is used to determine if the means of these two groups differ. We can do this by comparing the difference between the two means with the standard error of the difference in the means of different samples. To compare the means of responses to each question in two samples, independent-sample T-Test is used to show whether the difference in the variances of the two samples in each question is statistically significant. The test results demonstrate that the variances of several questions (Q6, Q7, Q8, Q10, Q12, Q14, and Q17) are statistically different. Since their $p$ values of Levene's test are 0.824, 0.149, 0.918, 0.576, 0.071, 0.395 , and 0.535 respectively. They are significant with two-tailed $p$ values of $0.000,0.002,0.009,0.010,0.001,0.001$, and 0,023 respectively. In other words, it is concluded that there are significant differences in attitude responses to Question6, 7, 8, 10, 12, 14, and 17 between teachers and students.

Back to question analyses in the above two sections, these significant differences can be proved by the responses of the two samples. To question 6, responses from the two samples indicate that they go to two opposite extremes. 48 percent of the students expressed agreement or 'strong' agreement and 25 percent expressed disagreement. In contrast, the result in teacher sample shows the other extreme, that is, 51.9 percent expressed disagreement or 'strong' disagreement, whereas 26.9 percent expressed agreement or strong agreement. They have different opinions on the question. In question 7, responses show that the two samples have different degrees in agreeing or strongly agreeing with the statement. A very high percentage (93\%) of student sample either 'strongly agrees' or 'agrees' compared to 73.1 percent of the teachers who 'agreed' or 'strongly agreed'. This great percentage discrepancy indicates that students expect more Chinese when teachers explain the grammatical and lexical points. Question 8 and 10 show the same situation, 86 percent and 88 percent of the student sample expressed agreement or 'strong' agreement with each statement, whereas much lower percentages $(76.9 \%, 67.3 \%$ respectively) of the teacher sample expressed the same opinion. It is believed that students expect more Chinese when teachers explain the cultural topics, grammatical and lexical items, and something concerned with the lesson content.

To Question 12, responses elicited also show that they have different opinions on the question. Whereas $46 \%$ 'disagreed' or 'strongly disagreed', only $31 \%$ 'agreed' or 'strongly agreed', in comparison to $55.8 \%$ of the teachers who 'agreed' or 'strongly agreed' and 32.6\% 'disagreed'. The two samples also go to the opposite extremes in attitudes to the statement. To Question 14, responses to the statement show that whereas 25\% 'agreed', 43\% 'disagreed' or 'strongly disagree' and about one-third showed uncertainty. Compared to the teacher sample, much higher of the percentage (50\%) of the teachers showed agreement or strong agreement. It seems that students don't like the way the teacher uses to request them to be silent. Responses to question 17 also indicate that 39\% either 'disagreed' or 'strongly disagreed', and only $32 \%$ 'agreed' with the statement in comparison to $48.1 \%$ of the teacher sample who 'agreed'. The two samples also take different sides in agreement with the statement on the question.

All these results display that teachers and students have different opinions on some functions of the teachers' code-switching. It is important to note that they have different opinions to functions in relation to subject matter. They show disagreement in four of five questions (Question 6, 7, 8, and 10). These differences have been tested to be significant. 


\section{Conclusion}

This paper focuses on the attitudes to teachers' code-switching in EFL classroom in local secondary schools, as perceived by both a sample of 52 teachers and a sample of 100 students. It aims at finding out their opinions on when and why teachers code-switch in EFL classroom, and for what purposes.

With regard to teachers' attitudes, teachers' responses are first discussed and analyzed and their attitudes are towards CS are elicited. Some of the results obtained are contrary to expectations, especially the ones related to question 5 , Question6, Question12, Question17 and Question19. No more than half of the sample "agreed" or "strongly agreed" with these statements. One way to explain the unexpected results above lies in the fact that in the sample most of the teachers (86.5 percent of the total) are senior class teachers. They rarely switch to Chinese to discipline and praise the students, or comment on the students' responses.

With regard to students' attitudes, two aspects are also focused. First, we discussed students' attitudes to teachers' code-switching; second, we have compared their opinions with those of teachers. Table1 shows that students have the similar opinions with the teachers in most of questions. This accordance suggests that teachers and students have a similar positive attitude to teachers' code-switching in EFL classroom. However there are still discrepancies between the two samples in some question items. These discrepancies also suggest that the use of code-switching in EFL classroom should be adapting to the practical teaching.

\section{References}

Adendorff, R. (1993). Code-switching amongst Zulu-speaking teachers and their pupils: Its functions and implications for teacher education. Language and Education, 7(3), 141-161, doi:10.1080/09500789309541356, http://dx.doi.org/10.1080/09500789309541356.

Adendorff, R. (1996). The functions of code switching among high school teachers and students in KwaZulu and implications for teacher education. In Kathleen M. Bailey and Davie Nunan (Eds), Voices from the language classroom: Qualitative research in second language education (p. 388-405). New York: Cambridge University Press.

Arthur, J. (1994). English in Botswana primary classrooms: Functions and constraints. In C. Rubagumya (Ed). Teaching and Researching Language in African Classrooms (p. 63-78). Clevedon: Multilingual Matters.

Atkinson, D. (1993). Teaching Monolingual Classes. London: Longman.

Auerbach, E. (1993). Re-examining English only in the ESL classroom. TESOL Quarterly, 27(1), 9-32. doi:10.2307/3586949, http://dx.doi.org/10.2307/3586949.

Canagarajah, S. (1995). Functions of code-switching in ESL Classrooms: Socializing Bilingualism in Jaffna. Journal of Multilingual and Multicultural Development, 6(3), 173-195.

doi:10.1080/01434632.1995.9994599, http://dx.doi.org/10.1080/01434632.1995.9994599.

Cole, S. (1998). The use of L1 in communicative English classrooms. [Online] Available: http://langue.hyper.chubu.ac.jp/jalt/pub/tlt/98/dec/cole.html/file.

Cook, V. (2001). Second Language Learning and Language Teaching. London: Arnold.

Cummins, J. \& M. Swain. (1986). Bilingualism in Education. Harlow: Longman.

Ferguson, G. (2003). Classroom code-switching in postcolonial contexts: Functions, attitudes and polices. AILA Review, 16, 38-51. doi:10.1075/aila.16.05fer, http://dx.doi.org/10.1075/aila.16.05fer.

Goffman, E. (1974). Frame Analysis. New York: Harper and Row.

Hussein, Riyad F. (1999). Code-alteration among Arab college students. World Englishes, 18(2), 281-289. doi:10.1111/1467-971X.00141, http://dx.doi.org/10.1111/1467-971X.00141.

Lin, A. (1996). Bilingualism or linguistic segregation? Symbolic domination, resistance and code-switching in Hong Kong schools. Linguistics and Education, 8, 9-84. doi:10.1016/S0898-5898(96)90006-6, http://dx.doi.org/10.1016/S0898-5898(96)90006-6.

Martin, P. (1999). Bilingual unpacking of monolingual texts in two primary classrooms in Brunei Darussalam. Language and Education, 13(1), 38-58. doi:10.1080/09500789908666758, http://dx.doi.org/10.1080/09500789908666758.

Pennington, M. (1995). Pattern and variation in use of two languages in the Hong Kong secondary English class. RELC 
Journal, 80-105. doi:10.1177/003368829502600205, http://dx.doi.org/10.1177/003368829502600205.

Poplack, S. (1980). Sometimes I'll start a sentence in English y termino en espanal: toward a typology of code-switching. Linguistics, 18, 581-616. doi:10.1515/ling.1980.18.7-8.581, http://dx.doi.org/10.1515/ling.1980.18.7-8.581.

Romaine, S. (1989). Bilingualism. Oxford: Blackwell.

Schmitt, N \& M, McCarthy, eds. (1997). Vocabulary: Description, Acquisition and Pedagogy. Cambridge: Cambridge University Press.

Simon, D. (2001). Towards a new understanding of code-switching in the foreign language classroom. In Jacobson, D. (Ed), Code-switching worldwide II (p.311-342). Berlin, New York: Mouton de Gruyter.

Weschler, R. (1997). Uses of Japanese (L1) in the English classroom: Introducing the Functional-Translation Method.

The Internet TESL Journal. Vol. III. No. II. [Online] Available:

http://www.aitech.ac.jp/ iteslj/Articles/Weschler-UsingL1.html/file

Willis, J. (1981). Teaching English through English. Harlow: Longman.

Table 1. Contrast of teachers and students' attitudes toward teachers' CS

\begin{tabular}{|c|c|c|c|c|c|c|c|c|c|c|}
\hline \multirow[t]{2}{*}{ Questions } & \multicolumn{2}{|c|}{$\begin{array}{l}\text { Strongly agree } \\
\text { (\%) }\end{array}$} & \multicolumn{2}{|c|}{ Agree (\%) } & \multicolumn{2}{|c|}{ Not sure (\%) } & \multicolumn{2}{|c|}{ Disagree (\%) } & \multicolumn{2}{|c|}{$\begin{array}{l}\text { Strongly disagree } \\
\text { (\%) }\end{array}$} \\
\hline & $\mathrm{T}$ & $S$ & $\mathrm{~T}$ & $\mathrm{~S}$ & $\mathrm{~T}$ & $S$ & $\mathrm{~T}$ & $S$ & $\mathrm{~T}$ & $\mathrm{~S}$ \\
\hline Q1 & 40.4 & 46 & 40.4 & 47 & 15.4 & 5 & 3.8 & 2 & 0 & 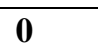 \\
\hline Q2 & 0 & 3 & 9.6 & 13 & 21.2 & 19 & 51.9 & 38 & 17.3 & 27 \\
\hline Q3 & 0 & 4 & 11.5 & 13 & 23.1 & 19 & 40.4 & 33 & 25 & 31 \\
\hline Q4 & 0 & 2 & 5.8 & 10 & 21.2 & 8 & 51.9 & 40 & 21.2 & 40 \\
\hline Q5 & 11.5 & 14 & 34.6 & 28 & 32.7 & 39 & 19.2 & 18 & 1.9 & 1 \\
\hline Q6 & 3.8 & 17 & 23.1 & 31 & 21.2 & 27 & 40.4 & 21 & 11.5 & 4 \\
\hline Q7 & 25 & 45 & 48.1 & 48 & 11.5 & 2 & 13.5 & 2 & 1.9 & 3 \\
\hline Q8 & 17.3 & 37 & 59.6 & 49 & 13.5 & 10 & 9.6 & 4 & 0 & $\mathbf{0}$ \\
\hline Q9 & 19.2 & 27 & 57.7 & 54 & 11.5 & 14 & 11.5 & 4 & 0 & 1 \\
\hline Q10 & 19.2 & 37 & 48.1 & 51 & 25 & 6 & 7.7 & 4 & 0 & 2 \\
\hline Q11 & 11.5 & 18 & 59.6 & 51 & 15.4 & 23 & 13.5 & 7 & 0 & 1 \\
\hline Q12 & 23.1 & 2 & 32.7 & 29 & 11.5 & 23 & 28.8 & 33 & 3.8 & 13 \\
\hline Q13 & 5.8 & 10 & 48.1 & 31 & 25 & 32 & 17.3 & 22 & 3.8 & 5 \\
\hline Q14 & 9.6 & $\mathbf{0}$ & 40.4 & 25 & 23.1 & 32 & 23.1 & 32 & 3.8 & 11 \\
\hline Q15 & 19.2 & 13 & 48.1 & 53 & 19.2 & 22 & 13.5 & 9 & 0 & 3 \\
\hline Q16 & 11.5 & 6 & 38.5 & 34 & 23.1 & 34 & 25 & 19 & 1.9 & 7 \\
\hline Q17 & 13.5 & 5 & 34.6 & 27 & 23.1 & 29 & 26.9 & 30 & 1.9 & 9 \\
\hline Q18 & 21.2 & 14 & 48.1 & 57 & 21.2 & 20 & 9.6 & 9 & 0 & $\overline{0}$ \\
\hline Q19 & 13.5 & 9 & 32.7 & 44 & 23.1 & 27 & 28.8 & 18 & 1.9 & 2 \\
\hline Q20 & 19.2 & 23 & 46.2 & 43 & 15.4 & 21 & 15.4 & 9 & 3.8 & 4 \\
\hline
\end{tabular}

T=teachers; $\mathrm{S}=$ students; $\mathrm{Q}=$ Question. 
Appendix: Questionnaire

Introduction: In this section, there are 20 questions on the attitudes to the teachers' code-switching in foreign language classroom. Teacher's Code-switching in Classroom is presented in the following example:

Teacher: This time, if you cannot answer my question

刚才有些同学如果不能回答我的问题呢

(Just now, some classmates, if can’t answer my question?)

Maybe because there are some new words in it

有些生词, 是吗?

(There some new words, aren't there)

Ok, now look at it again

In the following questions we would like you to answer by simple giving marks from 5 to 1 . For example, in the following questions, If you Strongly agree the opinion in the question, tick ' 5 ' in the check, If you Strongly disagree the opinion in the question, tick ' 1 ' in the check,

5=strongly agree; $\quad$ 4=agree; $\quad 3=$ not sure; $\quad 2=$ disagree; $\quad 1=$ strongly disagree

\section{Part 1 Teacher' persona}

Question1

Teachers who switch codes from English to Chinese or from Chinese to English can express themselves clearly in both languages.

\begin{tabular}{|l|l|l|l|l|}
\hline 5 & 4 & 3 & 2 & 1 \\
\hline
\end{tabular}

Question2

Teachers who switch codes from Chinese to English or from English to Chinese may cause difficulty in understanding.

\begin{tabular}{|l|l|l|l|l|}
\hline 5 & 4 & 3 & 2 & 1 \\
\hline
\end{tabular}

Question3

Teachers who switch codes from English to Chinese or from Chinese to English pollute languages.

\begin{tabular}{|l|l|l|l|l|}
\hline 5 & 4 & 3 & 2 & 1 \\
\hline
\end{tabular}

Question4

Teachers who switch codes from English to Chinese are deficient in English.

\begin{tabular}{|l|l|l|l|l|}
\hline 5 & 4 & 3 & 2 & 1 \\
\hline
\end{tabular}

Question5

Teachers who switch codes from English to Chinese are proficient in English.

\begin{tabular}{|l|l|l|l|l|}
\hline 5 & 4 & 3 & 2 & 1 \\
\hline
\end{tabular}

\section{Part 2 Subject access}

Question6

Teachers who switch codes from Chinese to English or from English to Chinese can do so in all kinds of topics in class.

\begin{tabular}{|l|l|l|l|l|}
\hline 5 & 4 & 3 & 2 & 1 \\
\hline
\end{tabular}

Question7

Teachers who switch codes from English to Chinese can better explain the grammatical points and lexical items in the text.

\begin{tabular}{|l|l|l|l|l|}
\hline 5 & 4 & 3 & 2 & 1 \\
\hline
\end{tabular}

Teachers who switch codes from English to Chinese can better explain cultural topics in the text.

\begin{tabular}{|l|l|l|l|l|}
\hline 5 & 4 & 3 & 2 & 1 \\
\hline
\end{tabular}


Question9

Teachers who switch codes from English to Chinese can better elicit responses from students.

\begin{tabular}{|l|l|l|l|l|}
\hline 5 & 4 & 3 & 2 & 1 \\
\hline
\end{tabular}

\section{Question10}

Teachers who switch codes from English to Chinese can better clarify the lesson content taught.

\begin{tabular}{|l|l|l|l|l|}
\hline 5 & 4 & 3 & 2 & 1 \\
\hline
\end{tabular}

\section{Part3 Classroom management}

\section{Question11}

Teachers who switch codes from English to Chinese can better clarify task instruction.

\begin{tabular}{|l|l|l|l|l|}
\hline 5 & 4 & 3 & 2 & 1 \\
\hline
\end{tabular}

Question12

Teachers who switch codes from English to Chinese can better discipline the students.

\begin{tabular}{|l|l|l|l|l|}
\hline 5 & 4 & 3 & 2 & 1 \\
\hline
\end{tabular}

\section{Question13}

Teachers who code-switch from English to Chinese can better engage students' attention.

\begin{tabular}{|l|l|l|l|l|}
\hline 5 & 4 & 3 & 2 & 1 \\
\hline
\end{tabular}

Question14

Teachers who switch codes from English to Chinese can better request quiet.

\begin{tabular}{|l|l|l|l|l|}
\hline 5 & 4 & 3 & 2 & 1 \\
\hline
\end{tabular}

Question15

Teachers who switch codes from English to Chinese can better direct (call on) students.

\begin{tabular}{|l|l|l|l|l|}
\hline 5 & 4 & 3 & 2 & 1 \\
\hline
\end{tabular}

\section{Part4 CS for interpersonal relations}

\section{Question16}

Teachers who switch codes from English to Chinese can better encourage students.

\begin{tabular}{|l|l|l|l|l|}
\hline 5 & 4 & 3 & 2 & 1 \\
\hline
\end{tabular}

\section{Question17}

Teachers who switch codes from English to Chinese can better praise students.

\begin{tabular}{|l|l|l|l|l|}
\hline 5 & 4 & 3 & 2 & 1 \\
\hline
\end{tabular}

Teachers who switch codes from Chinese to English or from English to Chinese can better enliven the atmosphere of class (e.g. make a joke for humor).

\begin{tabular}{|l|l|l|l|l|}
\hline 5 & 4 & 3 & 2 & 1 \\
\hline
\end{tabular}

Question19

Teachers who code-switch from English to Chinese can better comment on the students' response.

\begin{tabular}{|c|l|l|l|l|}
\hline 5 & 4 & 3 & 2 & 1 \\
\hline
\end{tabular}

Teachers who switch codes from English to Chinese can better negotiate with students (reduce distance).

\begin{tabular}{|l|l|l|l|l|}
\hline 5 & 4 & 3 & 2 & 1 \\
\hline
\end{tabular}

